\title{
Solid Biofuels in Residential Heating Appliances and Related Air Pollution in Northern Italy
}

\author{
Veronica Galantucci ${ }^{1}$, Van Minh Duong ${ }^{2 *}$ \\ 'Polytechnic University of Milan, Piazza Leonardo da Vinci, 32, 20133 Milano MI, Italy \\ ${ }^{2}$ University of Chemistry and Technology Prague, Technická 5, 16628 Prague 6, Czech Republic
}

Received: 27 November 2020

Accepted: 25 January 2021

\begin{abstract}
The study extends recent knowledge in solid biofuels and residential heating applications as they play a crucial role in air pollution at the regional level in northern Italy. Comparative evaluation with popular firewood and market-based pellets showed similar heating values (17-18 MJ/kg) and relatively low mass fractions of ash contents (1\%). Low chlorine and sulfur contents, the adequate mass fraction of nitrogen were indicated in correlation with potential gaseous pollutants. Comprehensive analysis on spatial distribution at provincial and municipal scales in relation to settlement size and geographical altitude details were used as an insight inventory approach. Residential solid biofuel combustion appliances contribute $43 \%$ of the total emission of solid particles, approximately five times more than industrial combustion units, while it contributes about $6 \%$ of the total energy consumption in the region. The importance of solid fuel substitution by specific fuel standards, low emission technology innovation, proper installation, and improved maintenance were discussed in a novel approach to direct emission control. Emission standards, strategic measures, legislative interventions, and future perspectives were emphasized as complementary instruments providing a significant step to enable effective pollution reduction in the residential heating sector.
\end{abstract}

Keywords: biomass, solid biofuel, residential heating, air pollution, particulate matter

\section{Introduction}

The global bioenergy reviews indicated that besides the conventional energy options of coal, oil, and natural gas, the utilization of viable biomass plays an important role in future energy [1]. Moreover, the substitution of fossil fuels also reduces greenhouse gases emission, as currently promotes the policy framework of climate change mitigation [2]. Specifically, in the modern

*e-mail: Van.Minh.Duong@vscht.cz economy of Italy, the implementation of the "Biomass Action Plan" published by the European Union [3] increases biomass utilization over many other renewable energy sources [4].

Subsequently, in the primary energy consumption in Italy today, there is a high rise of natural gas to a fraction of 34\% (approximately 60 Mtep with an annual average growth rate of $1.6 \%$ ), followed by the renewable energy sources in a fraction of $18 \%$ (over 32 Mtep with an annual average growth rate of $9.6 \%$ ) [5]. This rapid growth confirms the diversification of biomass targeting bioenergy production, partly contributes to the energy demand and security. 
In recent years, the energy policy in Italy targeting heat generation and electricity production has partially transformed towards progressive de-carbonization approaches. On this point, previous studies described solid biofuel as the carbon neutral form considering energy conversion routes and engineering processes [6, 7]. The statistical figures indicate the annual domestic consumption of biomass in Italy was 20 million tons, equivalent to a fraction of $14 \%$, the second running up behind natural gas [8]. Besides its wide availability, advantages of low cost, and less dependence on shortterm weather changes, the promotion on economic structure and provision of additional income for local farmers were further addressed as considerable factors.

From the viewpoint of essential energy services required, the rapid growth of sustainable bio-economy constantly raises the demands of renewable energy diversification [9]. However, it has to be considered that recent thermochemical conversion routes and processes of solid biofuels, particularly combustion systems with low efficiency and inadequately emission control, are high potential sources of gaseous pollutants and solid particles emission. In Lombardy, an industrialized and highly populated region (9 million inhabitants) in northern Italy, the importance of small-scale residential appliances has been evidently highlighted as a major contributing sector of municipal emissions either in inventory data on the regional and national scales [10-12].

Early studies confirmed the significant distribution of residential combustion on the total emission of particulate matter and gaseous pollutant emission in northern Italy $[13,14]$, as summarized in Fig. 1. The emission of $\mathrm{NO}_{\mathrm{x}}$ from household activities $(9 \%)$ is generally lower than that from industrial combustion $(17 \%)$, road transport $(53 \%)$, or other mobile sources (11\%). However, the residential sector appears to be the most important contributor to the total emission of $\mathrm{PM}_{10}$ in the Lombardy region with the fraction of $43 \%$. The contribution of residential heating and cooking activities is $20 \%$ of various greenhouse gases based on $\mathrm{CO}_{2}$ equivalent value, higher than energy production sector and refineries combined.

Therefore, the research work is essential to address topical issues related to solid biofuel combustion, validate residential heating applications, and outline the potential emissions of solid particles and gaseous pollutants in northern Italy. Besides the investigation on available technical measures, technology options, and proposed emission factors, the focus on policy perspectives identifies instrumental baselines to enable the effectiveness of pollution reduction. Thereby, the comprehensive evaluation and insight assessment essentially extend the principal information and database to support further implications and projection of bio-economy in the region.

\section{Material and Methods}

\section{Solid Biofuel Characterization}

Residential heating with woody biomass continues being the essential practice in municipalities in northern

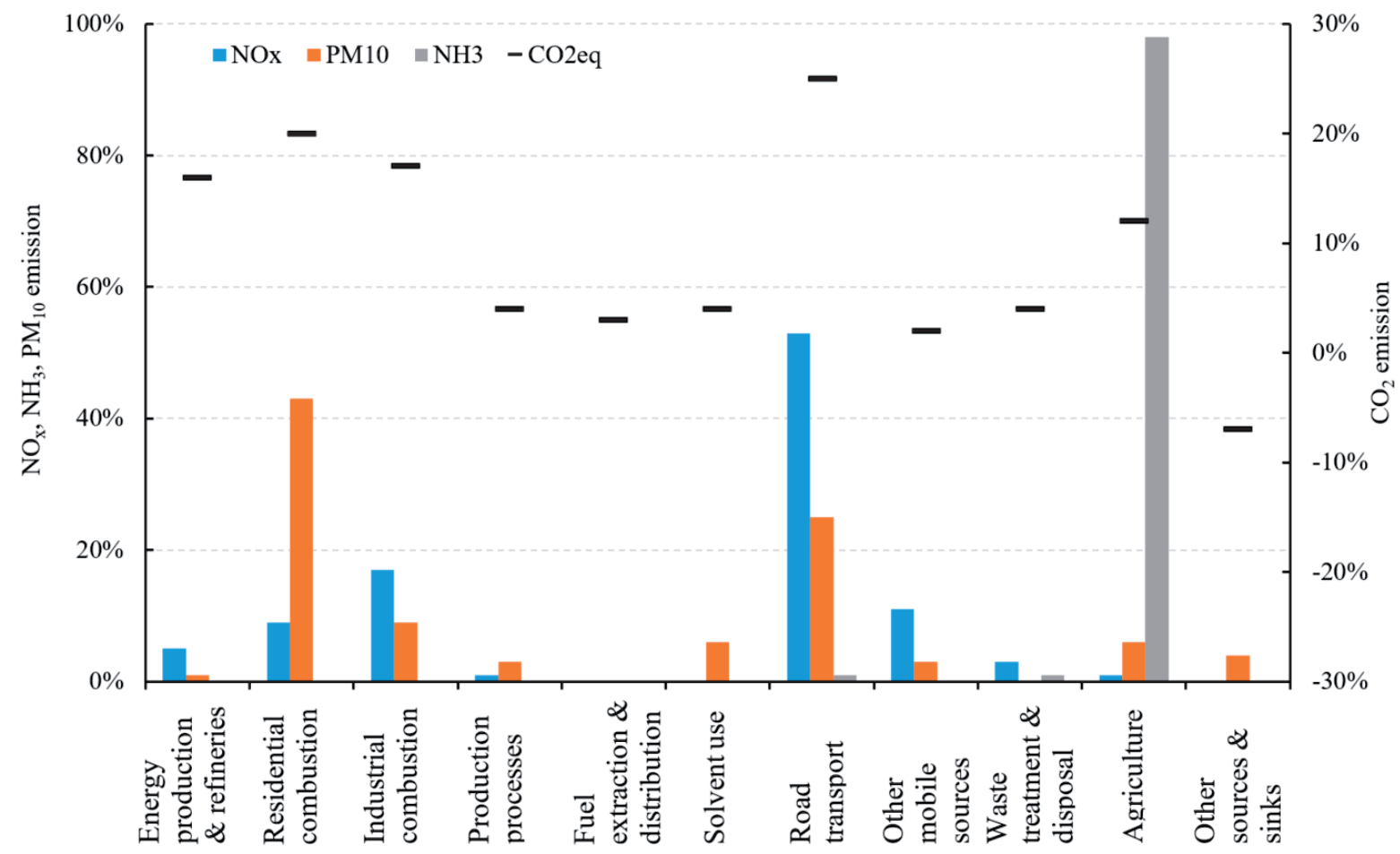

Fig. 1. Sectoral contributions on major air pollutants in northern Italy. 


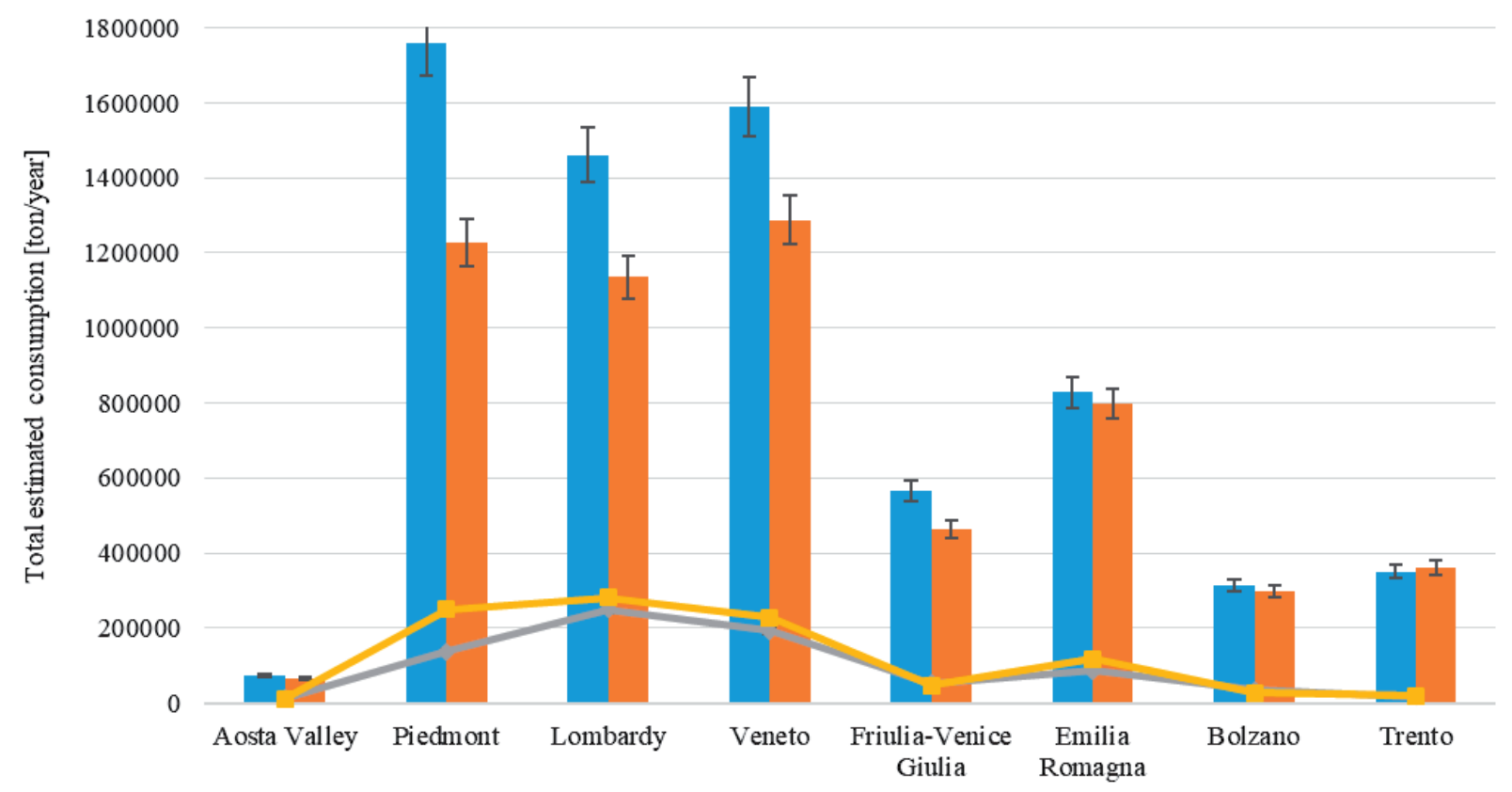

Wood comsumption 2013 Wood consumption 2019

$\longrightarrow$ Pellet consumption $2013-$ Pellet consumption2019

Fig. 2. Solid biofuels consumption distributed in municipalities in northern Italy.

Italy even with the widespread availability of natural gas. Early statistical assessments with computer-based survey methods primarily characterized total and local distributions of solid biofuels consumption in northern Italy $[8,15]$. Fig. 2 provides a comparative overview of the estimated average consumption of wood and pellets in the targeted municipalities.

The pattern of solid biofuels consumption shows a significant shift in total domestic use in the Lombardy region, confirmed by a reduction of wood consumption from 1.46 million tons in 2013 to approximately 1.14 million tons in 2019. As expected, a number of households start using pellets as an alternative, especially in highly urbanized provinces. At this transition stage, the annual pellets consumption increased from 250 thousand tons in 2013 to 282 thousand tons in 2019. The graphical enhancement of error bars visualizes the greater variation of wood reported on the mountain areas regularly for energy purposes compared to the hill and plain areas with various energy options. From the energetic viewpoint, it is important to note that domestic heating was the primary utilization of solid biofuels rather than cooking in Lombardy. For this reason, households intend to use pellets more frequently in the future, considering the economic factors, technological changes, and personal aesthetic comfort.

The key parameters of the popular firewood types in the Lombardy region that practically fed in the household appliances were summarized in Table 1. The two commercial types of low- and high-quality wood pellets were characterized as market-based solid biofuels for the automatic feeding stove and boiler [16-18]. The certified high-quality pellets analysis shows lower ash content and mass fractions of sulfur and chlorine than those presented in the low-quality uncertified pellets, even though they released similar heating values.

The recorded net calorific values, in a range of 16.2 MJ/kg for False Acacia and oak to $17.6 \mathrm{MJ} / \mathrm{kg}$ for pellets indicate a potential heat release and influence of the process control during combustion, gasification and pyrolysis. The main components of solid biofuels, the carbon content, were determined with mass fractions in the typical ranges of $44 \%$ to $47 \%$, respectively, explaining the significant calorific values of woody biofuels reported, in comparison to other solid fuels. Mass fraction of hydrogen, ranging between 5.3\% for hornbeam and spruce and 5.6\% for False Acacia, respectively, on dry basis.

Nitrogen oxides, $\mathrm{HCl}, \mathrm{Cl}_{2}$, alkali chlorides formation, gaseous compounds of $\mathrm{SO}_{2}, \mathrm{SO}_{3}$, and alkali sulfates released during the combustion process are important not only for emission control but also in corrosion processes [19-20]. Emission and environmental issues can be controlled with the adequate nitrogen, low chlorine and sulfur mass fractions reported in the wood logs and pellets used on a dry basis, with exceptional attention for False Acacia and hornbeam.

Wood log moisture values are in a typical range of $9-10 \%$ indicated the potential correct practice in residential heating system in the region. Meanwhile, the low moisture content ranging between $6.8 \%$ for high-quality certified pellets and $7.1 \%$ for low-quality market available pellets specifies a minor influence 
Table 1. Physiochemical properties of common woody biofuel in northern Italy.

\begin{tabular}{|c|c|c|c|c|c|c|c|c|}
\hline Parameter & Beech & False Acacia & Hornbeam & Oak & Spruce & Pellet low quality & Pellet high quality \\
\hline \multicolumn{7}{|c|}{ General - mass fraction on wet basis } \\
\hline Moisture [\%] & 9.5 & 9.2 & 9.8 & 10 & 9.3 & 7.1 & 6.8 \\
\hline Ash content [\%] & 0.5 & 0.8 & 0.5 & 1.4 & 0.4 & 0.8 & 0.4 \\
\hline NCV [MJ/kg] & 16.5 & 16.2 & 16.4 & 16.2 & 16.9 & 17.6 & 17.5 \\
\hline \multicolumn{7}{|c|}{ Elemental analysis - mass fraction on dry basis } & 48.1 & 47.9 \\
\hline Carbon [\%] & 44.9 & 45.2 & 45.3 & 44.8 & 46 & 5.5 & 5.5 \\
\hline Hydrogen [\%] & 5.4 & 5.6 & 5.3 & 5 & 5.3 & 0.3 & 0.3 \\
\hline Nitrogen [\%] & 0.1 & 0.4 & $<0.1$ & $<0.1$ & 0.65 & 110 & 55 \\
\hline Sulfur [mg/kg] & 70 & 355 & 150 & 105 & 40 & $<5$ & 30 \\
\hline Chlorine [mg/kg] & $<10$ & 170 & 30 & $<10$ & 20 & & \\
\hline
\end{tabular}

in the combustion behavior; the volume of flue gas produced and the average residence drying time before gasification takes place.

The recorded mass fractions of ash contents, usually $<1 \%$ except $1.4 \%$ for oak, indicate minor influence on the combustion technology applied, de-ashing process, transport, storage, utilization and disposal of the produced ash. Those low values usually lead to low particulate matter emission, as a minor influence on the heat exchanger design, cleaning system, and solid particle control technology. The pellets quality (on the basis of ash, sulfur, and chlorine contents) has significant influence on the emission level of the automatic pellet stoves and boilers.

Previous research findings indicated the similar emission characteristics of commercial woody biofuel types in the manual feeding units $[18,19]$. Thus, research attention on the actual emission related to the firewood seasoning more than the fuel type was extended.

\section{Combustion Appliances}

Most solid biofuels are combusted at a relevant temperature in small-scale appliances, such as household stoves, small boilers for single heating purposes. The commercial products of residential heating appliances commonly used in Italy are woody biomass-fired devices [21]. Manual feeding installations burn wood logs while automatic models fed with selected wood pellets. Fig. 3 presents the relative fraction of residential appliances spatially distributed among major municipalities in northern Italy.

Traditional devices including open and closed fireplaces, wood stoves, and modern pellet stoves are rather equally distributed in the Lombardy region (fractions of $20 \%, 21 \%, 26 \%$, and $22 \%$, respectively) whereas, wood stoves are still commonly installed in many other regions. The error bars graphically enhance the significant difference within the majority of these conventional appliances among the investigated regions.

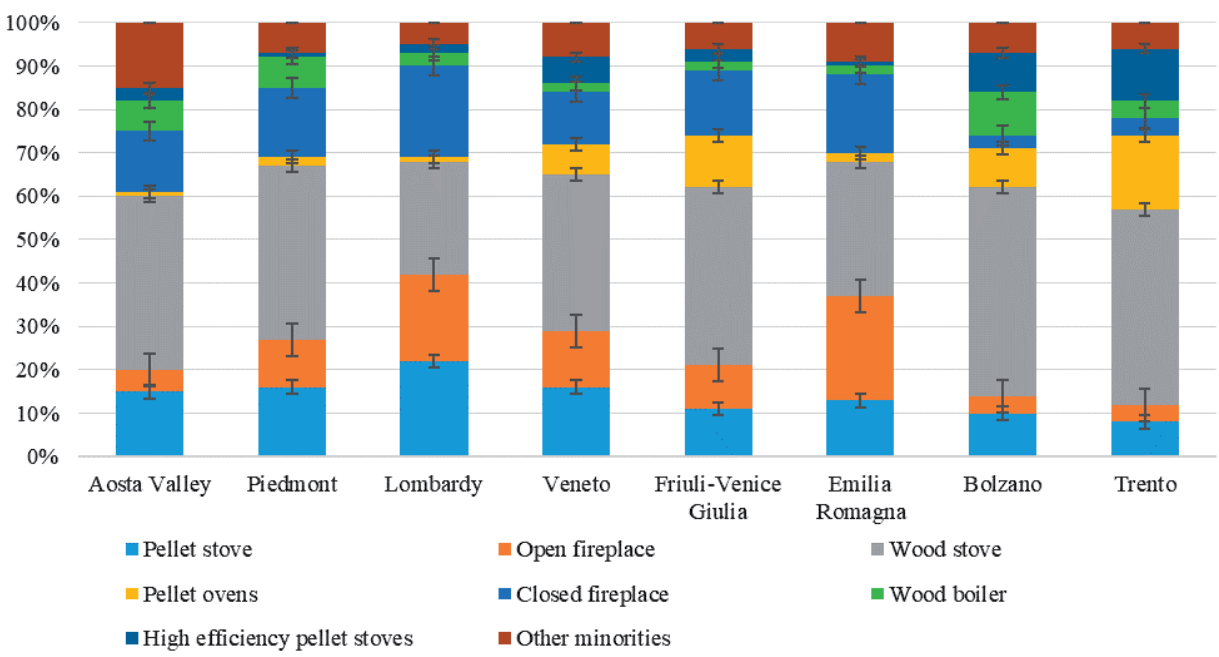

Fig. 3. Provincial and municipal distribution of residential appliance types in northern Italy. 
However, remarkable small fractions of pellet ovens, high efficiency pellet stoves, and especially boilers ( $1 \%$, $2 \%$, and $3 \%$, respectively) were previously reported in Lombardy compared to Friuli-Venice Giulia, provinces of Bolzano and Trento.

Table 2 summarizes the technological parameters of representative commercial appliances that commonly used in northern Italy as residential heating units. Open fireplaces burning wood logs with nominal heat output less than $10 \mathrm{~kW}$ are still popular in Lombardy but do not actually provide net heating efficiency in most circumstances, consequently they are commonly characterized as recreational units rather than space heating. The traditional and advanced stoves with a higher energy efficiency approximately of $70-75 \%$, respectively, are classified as similar wood log feeding models, since they practically have natural convection heat transfer and nominal heat output less than $10 \mathrm{~kW}$.

Closed fireplaces with a nominal heat output greater than $10 \mathrm{~kW}$ were considered as new featured models, equipped with a forced air convection heat exchanger and secondary combustion air control options [18]. The most popular models in the Italian market in recent years are automatic feeding pellet stoves with a considerable energy efficiency of $90 \%$. The technology advanced appliances are the automatic pellet boilers, since they are equipped with lambda probe and the highest energy efficiency of $95 \%$.

\section{In-situ Emission}

A number of sources confirmed the design of small-scale heating models, especially the primary and secondary air supply directly influences the emission level [22]. However, several experimental works observed only a slightly lower $\mathrm{CO}$ and particulate matter emission, but significant higher gaseous pollutants, particularly $\mathrm{NO}_{\mathrm{x}}$ and $\mathrm{PAH}$ [23-25] from the new featured models.

In practice, combustion- related parameters in closed fireplaces, traditional ovens, and advanced stoves are essentially similar, so that emission values in circumstances of no available data were assumed in the same range. However, the combustion process in open fireplaces is considered substantially different to other types, particularly temperature and excess draft air. Nevertheless, inventory reports noted that very few data concerning fireplaces were available despite the fact this is primary type in northern Italy $[26,27]$.

In addition, different conditions and methods of measurement were applied for establishing emission factors. Particularly, emission of particulate matter could be defined as consisting of filterable and condensable fractions. Whereas, emission factors derived from dilution tunnel determinations always indicate higher values of total particulate matter. Considering the net effect on emission factors for small-scale combustion units, the significant difference is for traditional wood fireplaces, stoves, and boilers, while smaller for automatic feeding pellet models [28]. Therefore, the reliable balance between the key input factors of solid biofuels, combustion parameters, and associated emission factors plays a key role in emission prediction.

In different experimental studies on residential wood combustion in the Lombardy region, average emission factors were used as a set of alternative values for the assessment of open and closed fireplaces, traditional stoves as well pellet stoves since they seemed to represent coherently the differences in appliance types [29]. Furthermore, empirical measurement data on pellet automatic stoves was proposed to verify the recent emission factors representing the technological standard [30]. For this reason, the empirical emission factors used in the regional inventory needed to be adjusted to represent the realistic operation condition.

Based on the previously published solid biofuel consumption statistics, the integrated greenhouse gas-air pollution interactions and synergies model was used to reproduce the total emission of fine particles from small-scale combustion sources in Italy and further predicted projection to 2050 in two different effort scenarios. These emission scenarios were assessed on the assumptions of future increase in the use of solid biofuels for thermal combustion in the residential sector. The first energetic baseline scenario

Table 2. Representatives of the most common residential heating appliances available in northern Italy.

\begin{tabular}{|c|c|c|c|c|c|c|}
\hline Appliance & Feeding fuel & $\begin{array}{c}\text { Air } \\
\text { regulation }\end{array}$ & Combustion air & Heat transfer & $\begin{array}{c}\text { Nominal heat } \\
\text { output }[\mathrm{kW}]\end{array}$ & $\begin{array}{c}\text { Energy efficiency } \\
{[\%]}\end{array}$ \\
\hline Open fireplace & Wood log & Manual & Natural draft & Natural convection & $<10$ & 50 \\
\hline Traditional stove & Wood log & Manual & Primary & Natural convection & $<10$ & 70 \\
\hline Advanced stove & Wood log & Manual & Primary and secondary & Natural convection & $<10$ & 75 \\
\hline Closed fireplace & Wood log & Manual & Primary and secondary & $\begin{array}{c}\text { Forced air and natural } \\
\text { convection }\end{array}$ & $>10$ & 80 \\
\hline Stove & Pellets & Automatic & Primary and secondary & Forced air & $<10$ & 90 \\
\hline Boiler & Pellets & Automatic & Lambda probe & Water & $>10$ & 95 \\
\hline
\end{tabular}


implied current efficient enforcement of committed legislations. Meanwhile, the maximum technically feasible reduction scenario implemented for the above baseline with the hypothesis of full substitution solid biofuels to highest quality pellets. This scenario aimed to highlight the residential sector relatively with respect to maximum policies and innovative technologies to minimize emission from domestic heating.

If all the best available advanced technological options were implemented, considering technical improvement and efficiency applications, a significant reduction by half of $\mathrm{PM}_{2.5}$ emissions from domestic heating sector would be achieved in the projection to 2050, relatively from an amount of 19.3 thousand of tons to 10.3 thousand of tons, as illustrated in Fig. 4. In fact, these optimistic comparative scenarios show significant changes in total emission trends. Moreover, the detailed resolution of statistical solid biofuels and related domestic appliances data enabled the prediction of total and local emissions of solid particles and gaseous pollutants from small-scale combustion sources in northern Italy [31, 32].

\section{Results and Discussion}

The strategy measures and best available technology implementation significantly restructured the residential heating systems in the northern Italy. The region simultaneously established the guidelines on installation according to the specific standard, periodically compulsory maintenance, and registration in the official database of all appliances. Several groups of relevant activities, including regulations and technologies have been addressed across municipalities in the Lombardy region to archive the less polluting forms of small-scale heating.

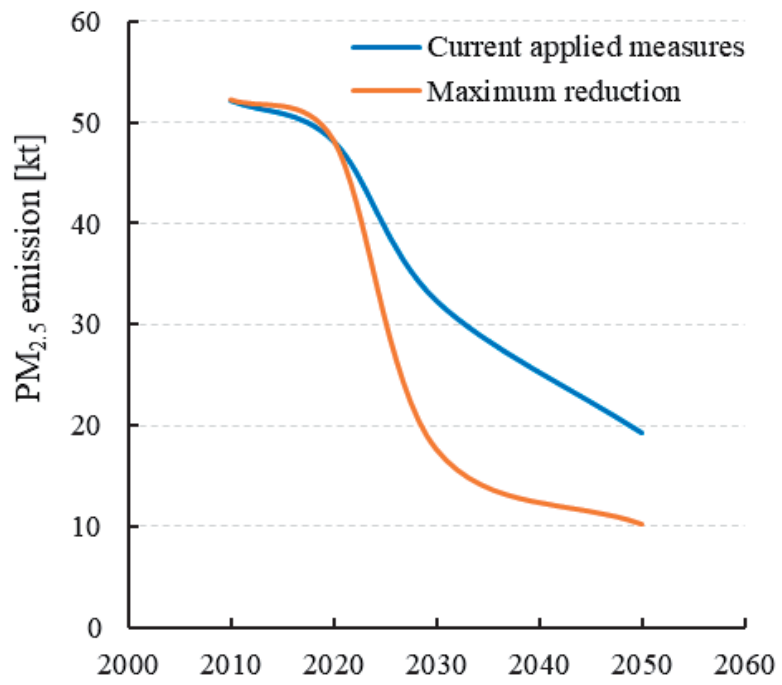

Fig. 4. Total emission of $\mathrm{PM}_{2.5}$ from residential solid biofuel fired appliances in projection to 2050 .
Regional statistical investigations provided the actual consumption of solid biofuels depended on a series of variables, typically the geographical altitude, population structure, and spatial distribution of residential appliance types, as grouped in Fig. 5. The municipality classification of mountain, hill, and plain was defined on the base of major categories established by the Italian national Institute of Statistics (ISTAT). This classification represents the number of inhabitants (by the groups of ten thousands), topographical altitude (hills are over $300 \mathrm{~m}$ high and mountains are over $600 \mathrm{~m}$ above the mean sea level), and settlement size. The greater numbers of residential appliances were reported in municipalities with population size less than 10000 inhabitants. Meanwhile, the more populated settlement size, the lower fractions of spatial distribution were obtained. Using this approach, the larger the consumption of solid biofuels, the higher estimated emissions in mountainous settlements, both in absolute terms and on a population basis.

The Lombardy region has adopted several regulatory measures to guarantee a proper installation and practice of individual appliances. Particularly, wood stoves and fireplaces with efficiency $<63 \%$ or volume fraction of $\mathrm{CO}$ emission $>0.5 \%\left(13 \% \mathrm{O}_{2}\right.$ ref.) in the agglomerations Milano, Bergamo, Brescia and all hill and mountain municipalities were forbidden from October 15 to April 15, implemented since 2007. Since 2015, new wood and pellet-fueled stoves must have an efficiency of at least $75 \%$ and $80 \%$, respectively [33].

Public training and information campaigns to raise the citizen's awareness of environmental-related issues of small-scale combustion systems and thus change their behavior in appropriate operation of household facilities were organized regularly targeting specific municipalities. With reference to the geographical altitude, higher consumption rates were reported in mountain areas, especially for wood stoves and closed fireplaces, whereas lower values were observed in plain and hill settlements. Sharing of local air quality information and pollution updates among solid biofuel end-users increased the perception of proper installation, good practice of operation, and maintenance [32]. Small-scale appliance owners identified requirements, experienced efficient burning techniques, and practiced effective emission control at all phases of the combustion cycle.

The estimated wood consumption, as illustrated in triangular markers in Fig. 5, was from 4 to 5 times higher than pellets used (presented in square markers) over the region. The required replacement of low-efficiency wood-burning appliances to new available technology of pellet ovens and boilers will certainly change these fractions. The governmental subsidies could be offered to local households to install new pellet appliances, heat pumps, automatic combined boilers, and further refurbish the heat distribution system, improve the building energy efficiency, additionally invest in low- 


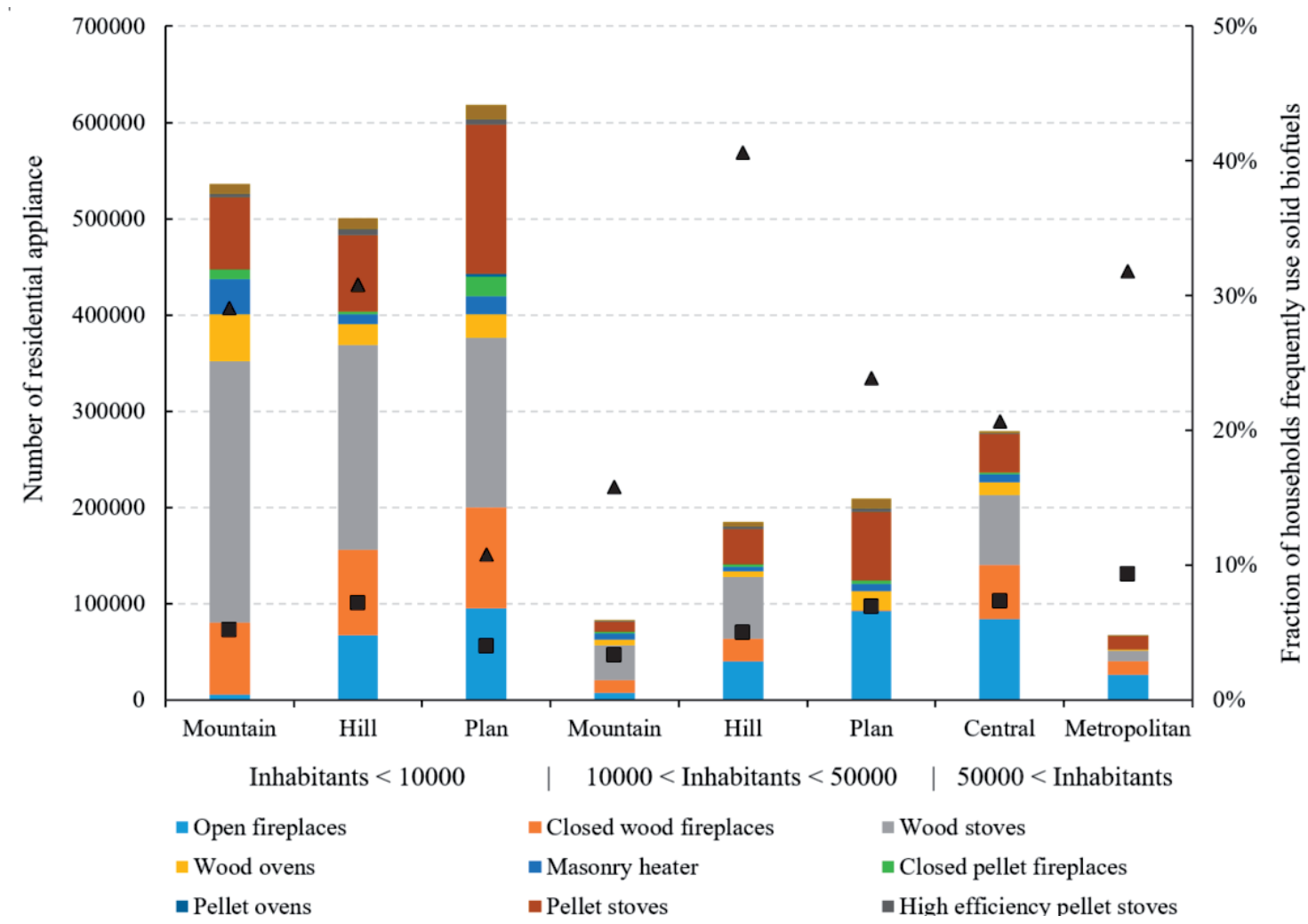

Fig. 5. Spatial distribution of solid biofuels and residential appliance types in northern Italy.

or zero-emission facilities. The installation rates of renewable-based heating installation supported by the government or regional authorities in the framework of housing and energy projects increased during the last few years. By these means, pellet stoves and boilers will be more common, especially in rural settlements with the population size of less than 10000 inhabitants.

Provisions of eco-designed certification for smallscale combustion units and eco-labelling for solid biofuel were essential, addressing particulate matter, gaseous criteria pollutants, and organic compounds. Moreover, old-type heating appliances below "2star" were banned of use, and the installation of new stove was limited to "3-star" from 2018. Following the progressive rolling schedule, old-type heating devices below "3-star" were banned of use, and the installation of new fireplaces and stoves was limited to "4-star" in 2020. On the other hand, burning of coal and high sulfur content fuel oil in small-scale appliances were prohibited, and thus incentives for the production of high-quality wood pellets had introduced. The solid biofuel palletization and characterization regarding sulfur, chlorine, ash, and metal contents were improved by standards.

Emission standards for residential combustion appliances regulate in-situ emission limit values are essentially with specific nominal heat output. Existing small-scale units exceeding the emission limits must be equipped with emission control modules or replaced with specific transition periods. The requirements for operation of domestic combustion plants with detailed guidelines are needed and regular inspection is essential. Municipalities where $\mathrm{PM}_{10}$ and/or benzo[a] pyrene exceeded limit values will not account for achieving the target of $50 \%$ energy from renewable sources from the next year on or without EU structural funds aimed. Those adopted measures in northern Italy were considered as a key control for effective emission reduction measures.

\section{Conclusions}

The research analyzed practical information on solid biofuels consumption in the northern Italy, at provincial and municipal scales, differentiated by population structure, geographical altitude, and spatial distribution variables. The obtained figures highlighted wood logs and pellets were the most commonly used solid biofuels, but wide-range thermal appliances was an important fact. An insight assessment with the inventory database of residential heating units at the local and regional levels beneficially enhanced the quality of estimation of related particulate matter and gaseous pollutant emissions in northern Italy.

Considering the emission factors and appliance efficiency, the study emphasized the importance of obtaining detailed information on the specific data of solid biofuels used and validated appliance models as a valuable statistical input for further emission inventory assessment. For this purpose, additional study should aim to the identification of equivalent emission factors 
and focus on uncertainty range as the key drivers in the development of high-quality emission data.

In further contribution, the insight assessment of average emission factors for small-scale residential combustion appliances considering local solid biofuel types, firing technology and practical end-user behavior typically of northern Italy provides the backbone for regional implications of incentive programmes for oldtype polluting device substitutions.

\section{Acknowledgements}

This research was carried out as a part of the mobility project, under the Key Action 1 of the Programme Erasmus Plus. The authors would express an appreciation to the European Commission for their contributions. Further acknowledgments would gratefully be extended to the analytical and modeling experts in the Polytechnic University of Milan and the University of Chemistry and Technology Prague for their excellent collaboration and consultancy during the mobility project.

\section{Conflict of Interest}

The authors declare no conflict of interest.

\section{References}

1. SCARLAT N., DALLEMAND J.F. The role of biomass and bioenergy in a future bioeconomy: Policies and facts. Environmental Development, 15, 3, 2015.

2. LUQUE R., DAVILA L.H. Biofuels: a technological perspective. Energy Environmental Science, 5, 542, 2008.

3. EUROPEAN COMMISION (EC). COM (2005) 628 final. Biomass Action Plan. 2005.

4. VIRDIS M.R., GAETA M., CIORBA U. Impatti energetici e ambientali dei combustibili nel riscaldamento residenziale. ENEA, 178, 2017.

5. KUENEN J., TROZZI C. Small scale combustion 2019 EMEP/EEA air pollutant emission inventory guidebook, 40, 2019.

6. MCKENDRY P. Energy production from biomass (part 1): overview of biomass. Bioresource Technology, 83 (1), 37, 2002.

7. KOJIMA T., ASSAVADAKORN P., FURUSAWA T. Measurement and evaluation of gasification kinetics of sawdust char with steam in an experimental fluidized bed. Fuel Processing Technology, 36 (3), 201, 1993.

8. PATTI S., PILLON S., INTINI B., SUSANETTI L. Action D3. Consumo residenziale di biomasse legnose nel bacino Padano. European Union Programme LIFE. PREAPAIR, 38, 2020.

9. EUROPEAN COMMISION (EC). Innovating for sustainable growth: a bioeconomy for Europe. Official Journal of European Union, 8 (2), 60, 2012.

10. CASERINI S., GIANI P., CACCIAMANI C., OZGEN S., LONATI G. Influence of climate change on the frequency of daytime temperature inversions and stagnation events in the Po Valley: historical trend and future projections. Atmospheric Research, 184, 15, 2017.

11. BERTINI I., FEDERICI A., FERRARI S., MANDUZIO L., MARTINI C., PANDOLFI E., POGGI M., PREZIOSI M., VIOLA C. Rapporto annuale efficienza energetica 2019. ENEA, Agenzia nazionale per le nuove tecnologie, l'energia e lo sviluppo economico sostenibile, 309, 2019.

12. LANZANI G., GURRIERI G.L. Air quality and climate actions: analysis and perspectives in the Lombardia Region. Beijing International Forum for Metropolitan Clean Air and Climate Actions, 24, 2019.

13. MINISTERO DELLO SVILUPPO ECONOMICO. Proposta di Piano Nazionale Integrato per L'energia e il Clima Italiano, 294, 2019.

14. CASERINI S. La combustione di legna in piccoli apparecchi domestici: impatti sulla qualità dell'aria e strategie di riduzione. Ingegneria dell'Ambiente, 5 (2), 127, 2018.

15. 1BUGANZA E., CARFAGNO N.R., GURRIERI G.L. Gli impatti ambientali della combustione di biomassa legnosa per la produzione di calore: le esperienze delle azioni di comunicazione nell'area del bacino padano e in Slovenia. PrepAIR project, LIFE program, 89, 2018.

16. MANCINI M., BERTON M., D'APOTE L., PARI L., LIBERATORI S., D'ANDREA S., CINI E., RECCHIA L., ACERBI M., MONNI M., GUIDOTTI R. Progetto Biomasse Enama realizzato con il contributo del Ministero delle Politiche Agricole e Forestali. Biomasse ed energia: capitolo 1 caratteristiche tecniche delle biomasse e dei biocombustibili, 16, 2008.

17. CICCARESE L., SPEZZATI E., PETTENELlA D. Le biomasse legnose: Un'indagine sulle potenzialità del settore forestale italiano nell'offerta di fonti di energia. APAT Agenzia per la protezione dell'ambiente e per i servizi tecnici, 93, 2003.

18. OZGEN S., CASERINI S., GALANTE S., GIUGLIANO M., ANGELINO E., MARONGIU A.M., HUGONY F., MIGLIAVACCA G., MORREALE C. Emission factors from small-scale appliances burning wood and pellets. Atmospheric Environment, 94, 144, 2014.

19. PERMCHART W., KOUPRIANOV V.I. Emission performance and combustion efficiency of a conical fluidized-bed combustor firing various biomass fuels. Bioresourse Technology, 92, 83, 2004.

20. DUONG V.M., PADOUVAS E. Solid biofuel characterization and ash properties of Acacia mangium, Paliva, 12 (1), 1, 2020.

21. CASERINI S., FRACCAROLI A., MONGUZZI A.M, ANGELINO E. New insight into the role of wood combustion as key PM source in Italy and in Lombardy region. In: 16th Annual International Emissions Inventory Conference "Emission Inventories: Integration, Analysis, and Communications" Raleigh, North Carolina, 16, 2007.

22. CASERINI S., LIVIO S., GIUGLIANO M., GROSSO M., RIGAMONTI L. LCA of domestic and centralized biomass combustion; the case of Lombardy, Italy. Biomass and Bioenergy, 34 (4), 474, 2010.

23. CASERINI S., GALANTE S., OZGEN S., CUCCO S., GREGORIO K.D., MORETTI M. A methodology for elemental and organic carbon emissions inventory and results for Lombardy region, Italy. Science of The Total Environment, 450, 22, 2013.

24. PASTORELLO C., CASERINI S., GALANTE S., DILARA P., GALLETI F. Importance of activity data for improving the residential wood combustion emission 
inventory at regional level. Atmospheric Environment, 45 (17), 2869, 2011.

25. DUONG V.M., FLENER U. Gaseous emission in automatic residential heating appliance using rice husks as solid biofuel. Paliva, 11 (3), 78, 2019.

26. BUONANNO G., MORAWSKA L., STABILE L., VIOLA A. Exposure to particle number, surface area and PM concentrations in pizzerias. Atmospheric Environment, 44, 3963, 2010.

27. MINISTERO DELLO SVILUPPO ECONOMICO. Proposta di Piano Nazionale Integrato per L'energia e il Clima Italiano, 238, 2017.

28. VAN DER GON D., BERGSTRÖM R., FOUNTOUKIS C. Particulate emissions from residential wood combustion in Europe - revised estimates and an evaluation. Atmospheric Chemistry and Physics, 15 (17), 6503, 2015.

29. GIANELLE V., COLOMBI C., CASERINI S., OZGEN S., GALANTE S., MARONGIU A., LANZANI G. Benzo(a) pyrene air concentrations and emission inventory in Lombardy region, Italy. Atmospheric Pollution Research, 4 (3), 257, 2013.
30. MARONGIU A., ANGELINO E., BELLINZONA S., LANZANI G. Methodology for Estimating Emissions from Small Domestic: Fuelwood Appliances in Lombardy. Chemical Engineering Transactions, 65, 115, 2018.

31. CIUCCI A., CIANCARELLA L., ZANINI G. The Italian optimization tool for the GAINS-Italy Model. ENEA report, 29, 2014.

32. AMANN M. Adjusted historical emission data, projection, and optimized emission reduction targets for 2030 - A comparison with COM data 2013. TSAP Report \#16a, Part A: Results for EU-28, 41, 2015.

33. AMANN M., COFALA J., KLIMONT Z., NAGL C., SCHIEDER W. Measures to address air pollution from small combustion sources. IIASA, 51, 2018.

34. PICCARDO M.T., CIPOLLA M., STELLA A., CEPPI M., BRUZZONE M., IZZOTTI A., VALERIO F. Indoor pollution and burning practices in wood stove management. Journal of the Air \& Waste Management Association, 64 (11), 1309, 2014. 